\title{
Normas sociales y dinámicas de poder en el hogar: movilidad y trabajo extra-doméstico de las mujeres en San Felipe del Progreso
}

Dynamic and social standards of home power: mobility and extra-domestic work of women in San Felipe de el Progreso

Normas sociais de poder e dinâmicas em casa: mobilidade e trabalho extradoméstico das mulheres em San Felipe del Progreso

\author{
Arlette Covarrubias Feregrino \\ El Colegio Mexiquense, A.C. México \\ arlette.cov@gmail.com
}

\section{Resumen}

Muchas mujeres mexicanas no pueden elegir con libertad sus idas y venidas ni tampoco su trabajo, lo que repercute en su bienestar. El objetivo de este artículo es analizar las normas sociales que influyen en las dinámicas de poder en el hogar y que guardan relación con la movilidad y el trabajo extra-doméstico de las mujeres del poblado de San Felipe del Progreso. Asimismo, se estudiaron los mecanismos de poder utilizados por los miembros del hogar en estas situaciones. Con este fin se realizaron entrevistas a profundidad a grupos de mujeres en la región, donde se encontró que las normas sociales determinan las tareas que deben cumplir las mujeres en el hogar, el poder de autoridad de sus esposos y familiares políticos, los argumentos utilizados en la negociación y, por tanto, los mecanismos y la visibilidad de las estrategias para ostentar el poder y oponerse a él.

Palabras clave: normas sociales, poder en el hogar, empoderamiento mujeres, trabajo extra-doméstico, movilidad. 


\section{Abstract}

Many Mexican women do not can choose freely their comings and goings or his work, with implications for their well-being. The aim of this article is to analyze the social norms that influence the dynamics of power at home that relate to the mobility and work extra - home of the women of the village of San Felipe de el Progreso. Also studied the mechanisms of power used by the members of the household in such situations. With this objective to women's groups in-depth interviews were carried out in the region, where it was found that social norms determine the tasks to be met by women in the home, the power of authority of their husbands and in-laws, the arguments used in the negotiation and, therefore, mechanisms and the visibility of strategies to hold power and oppose him.

Key Words: social norms, power at home, women empowerment, extra-domestic work, mobility.

\section{Resumo}

Muitas mulheres mexicanas não pode escolher livremente as suas idas e vindas, nem seu trabalho, o que afeta seu bem-estar. O objetivo deste trabalho é analisar as normas sociais que influenciam a dinâmica de poder em casa e que se relacionam com a mobilidade e extra-doméstico trabalho das mulheres na cidade de San Felipe del Progreso. Além disso, foram estudados os mecanismos de poder utilizados pelos membros do agregado familiar nessas situações. Para este fim entrevistas em profundidade com grupos de mulheres na região, onde verificou-se que as normas sociais determinar as tarefas a serem cumpridas pelas mulheres em casa, o poder de autoridade de seus maridos e sogros, os argumentos utilizados foram feitas mecanismos e estratégias de negociação e, portanto, de visibilidade para manter o poder e se opõem a ela.

Palavras-chave: normas sociais, de energia em casa, o empoderamento das mulheres, extra-domésticos, obras de mobilidade. 


\section{Introducción}

La libertad de movimiento y la posibilidad de elegir un trabajo extra-doméstico son fundamentales para el bienestar de las personas. También son el medio para conseguir otros logros, tales como la asociación con otras personas fuera del hogar, el desarrollo personal y de habilidades, la salud, etcétera. Sin embargo, muchas mujeres mexicanas, al igual que otras de muchos países del mundo, no pueden decidir libremente con respecto a su propia movilidad y trabajar fuera del hogar a cambio de una remuneración. García y Oliveira (1994, pp. 216-217) entrevistaron a mujeres de distintas localidades de México y encontraron que en los sectores populares tan sólo $44 \%$ de ellas tenía libertad para salir, trabajar, o participar políticamente, pero primero tenía que pedir permiso a su cónyuge. También encontraron que las principales fuentes de conflicto en el hogar se debían a infidelidad, celos y prohibición por parte del marido para salir sola.

La toma de medidas y la elaboración de programas que efectivamente empoderen a las mujeres en estas áreas de su vida son fundamentales para aumentar su bienestar y también para reducir la desigualdad y pobreza. Para lograrlo primero se deben entender las dinámicas de poder utilizadas en el hogar, y cómo inciden negativamente tanto en el bienestar como en la manipulación de las mujeres. Existen distintos mecanismos que pueden utilizarse para obtener y ejercer poder. Algunos de ellos son más violentos que otros, por ejemplo, la violencia física es más perniciosa para una persona que la manipulación a través de argumentos. Además, el poder puede manifestarse como un conflicto de intereses y, por tanto, ser visible, pero también puede haber obstáculos que impidan que los conflictos de intereses se exterioricen.

Las decisiones que las mujeres y los hombres toman a lo largo de sus vidas y las restricciones que enfrentan para poder tomarlas están relacionadas con su entorno cultural e histórico (Boserup, 1970). Las normas sociales, es decir, las reglas que dictan el comportamiento social correcto o incorrecto, determinan la capacidad de elección de las 
personas. En México, así como en el resto del mundo, dichas normas fijan el sistema jerárquico en el hogar, donde casi siempre las mujeres tienen menos libertad de elección.

El objetivo de este artículo es indagar la manera como las normas sociales influyen en las dinámicas de poder en el hogar, que están relacionadas con el movimiento y el trabajo extra-doméstico de las mujeres unidas en San Felipe del Progreso, un municipio mazahua con altos niveles de marginalidad y pobreza en el noroeste del Estado de México.

En una revisión literaria de estudios sobre poder y empoderamiento de las mujeres, Malhotra et al. (2005), encuentran que se han hecho pocos los estudios, fuera del sur de Asia, enfocados en la libertad de movimiento de las mujeres. Son más las investigaciones sobre la influencia del trabajo extra-doméstico en el poder de las mujeres en el hogar, y escasas sobre la negociación de las mujeres para trabajar a cambio de una remuneración económica. Gates (2002) encontró en la frontera norte de México que las mujeres negociaban con sus esposos la posibilidad de trabajar, ofreciendo a cambio hacer más labores domésticas o contribuir financieramente en gastos grandes como la construcción de una casa. Por otra parte, Kabeer (2000) señala que en Bangladesh el bienestar de los hijos es una estrategia común usada por las mujeres al negociar con sus esposos su actividad laboral en las fábricas textiles.

\section{Las normas sociales y el poder en el hogar ${ }^{1}$}

La definición de normas sociales que utilizaremos es la propuesta por Covarrubias (2016), basada en la conceptualización de Rutherforth (1996). Las normas sociales son reglas morales e informales (que tienen que ver con los principios del comportamiento bueno o malo) mostradas por una sociedad y que influyen en su internalización entre los miembros de un grupo de acuerdo a su grado de aprobación. La violación a una regla puede ser castigada con chismes, críticas y, en casos extremos, ostracismo o violencia. También puede crear sentimientos de culpabilidad o remordimiento en el individuo transgresor.

Las normas varían en su nivel de subjetividad, es decir, el grado en el que se naturalizan o internalizan en la sociedad. Bourdieu (1977, p.164) llamó “doxa” al momento en que las

\footnotetext{
${ }^{1}$ Este marco conceptual y teórico está basado en un artículo teórico enviado para su dictamen a una revista científica.
} 
normas han sido internalizadas en la sociedad, a tal grado que el orden establecido se percibe como autoevidente y natural, y no como una posibilidad. Él distingue a "doxa” de otras creencias que implican conciencia y reconocimiento de posibles creencias antagónicas. Dicho nivel de subjetividad determina el grado en que la norma se generaliza en la comunidad.

Por otra parte, el significado del concepto poder ha sido debatido ampliamente en las ciencias sociales. De acuerdo con Lukes (2005), esta palabra es polisémica, es decir, posee varios significados que se utilizan de forma distinta dependiendo de su contexto y aplicación. En ocasiones se utiliza para comunicar el poder de las cosas de existir y de actuar, mientras que en otras se utiliza para señalar el poder de una persona sobre otra. En el primer caso, Scott (2001, p.1) define el poder como el uso intencional de un agente para afectar la conducta de otros en las relaciones sociales. Las feministas utilizan la segunda conceptualización de poder, pero enfocado en el proceso de toma de poder o empoderamiento de las mujeres. Kabeer (1999, pp. 436-437) define este último término como la habilidad de un individuo o de grupo de personas para elegir en un contexto donde la elección ha sido descalificada. Este término se refiere a decisiones estratégicas de vida, o sea que son clave para que las personas puedan vivir la vida que desean. La libertad de movimiento y el poder elegir un trabajo extra-doméstico entran en este tipo de decisiones. Por otra parte, para que un individuo se empodere inicialmente tiene que estar desempoderado, es decir, la habilidad de toma de decisiones estratégicas es limitada (Kabeer, 1999).

Las relaciones de poder operan a distintos niveles en la sociedad: individual, familiar, comunitario, nacional e internacional (Malhotra et al., 2005). El presente artículo analiza las relaciones de poder en el hogar, enfocándose en la manera como los esposos o la familia política de las esposas usan (intencionalmente o no) su poder para manipular la conducta de éstas en su movimiento y trabajo extra-doméstico, y cómo ellas utilizan el poder para resistirlo.

Lukes (2005) definió tres dimensiones de poder que dependen de la visibilidad de las decisiones y del conflicto. Su estudiante Gaventa (2011) retomó estas tres dimensiones y las conceptualizó como formas de poder, las cuales se describen a continuación. 
Forma de poder visible: involucra decisiones controversiales sobre las que hay un conflicto explícito y observable. El conflicto es acerca de preferencias que presumiblemente se hacen conscientemente y que se manifiestan con acciones observables. Si se observa quién participa, cuáles son los intereses en juego, qué voces están presentes pero tienen poca influencia, quién pierde y quién gana, se puede dilucidar quién tiene el poder. En esta forma de poder, los actores son conscientes de sus agravios y son capaces de articularlos, por lo que tienen los recursos necesarios para negociar.

Forma de poder oculto: se refiere a la creación de barreras que previenen que se manifieste la participación en la toma de elecciones. Involucra mecanismos en los que una persona previene a otra de sacar a relucir un conflicto. También incluye acciones en las que personas resisten la dominación y lo hacen de forma menos pública.

Forma de poder invisible: involucra formas en las cuales el conocimiento de los derechos e intereses son escondidos a través de ideologías, formas de valor, y comportamiento determinados por patrones culturales y sociales, así como por la política de instituciones. Tiene que ver con la "internalización" de las normas sociales, y afecta a las personas en su conocimiento y consciencia de asuntos y conflictos potenciales. Debido a que los patrones de conducta culturalmente construidos no son establecidos por los miembros del hogar, no se puede hablar explícitamente del poder de uno sobre otro, por ejemplo, del esposo sobre la esposa; sin embargo, debido a que la libertad de la esposa para elegir bienestar está siendo restringida, se puede afirmar que se ejerce poder sobre de ella.

En el caso de una pareja hay poder visible, sobre todo cuando las dos personas entran en un proceso de deliberación en el que manifiestan sus inquietudes y deseos. Aquel que tiene poder es el que logra imponer sus intereses. Por otra parte, hay poder invisible cuando uno de los dos no expresa explícitamente sus intereses y no se entra en un proceso de negociación. El poder invisible está presente cuando una de las dos personas o las dos, internaliza completamente una norma social. Por ejemplo, las mujeres internalizan a tal grado sus roles de esposa y madre, que no los cuestionan.

Las estrategias para empoderar a los individuos dependen de la visibilidad de las formas de poder. Las maneras para desafiar el poder invisible incluyen la educación adulta, los programas de concientización, el uso de los medios de comunicación y los métodos 
populares para desafiar los estereotipos y discursos prevalentes. Cuando hay poder oculto, el individuo no tiene la agencia suficiente o la esperanza de lograr sus intereses usando mecanismos públicos y explícitos. Por lo tanto, los métodos que abordan este tipo de poder se enfocan en mejorar la voz de las personas y su capacidad de expresar y manifestar sus necesidades, es decir, de reforzar su agencia. Por último, cuando hay poder visible, se tienen la agencia y el espacio para externar cualquier inquietud. En este caso, la estrategia involucra la negociación directa y la provisión de recursos sociales, legales y económicos (Gaventa, 2011). Debido a las distintas implicaciones de cada una de estas formas de poder en los programas y las políticas que deben usarse para empoderar a las mujeres, a lo largo del artículo se hará una diferenciación.

Es importante también distinguir entre los mecanismos que pueden ser utilizados por los individuos para mantener y ejercer el poder. Los mecanismos utilizados en el poder visible y oculto son la coerción, la manipulación, la autoridad y la influencia. Una estructura de poder es la coerción, que descansa en la amenaza del uso de la fuerza o la privación seria por parte del principal, y en la creencia por parte del subalterno de que tiene tanto la capacidad como la disposición de usarla (Scott, 2001). La manipulación tiene que ver con el uso del engaño y la mentira para mantener el poder. Es un aspecto o sub concepto de la fuerza, donde la conformidad surge en ausencia del reconocimiento de la exacta naturaleza de la demanda que se le hace por parte de quien actúa de conformidad (Lukes, 2005). La autoridad es sostenida por la idea de que se tiene el derecho a dar órdenes y la correspondiente obligación de obedecer. Existe cuando una o varias personas tácitamente o explícitamente permiten que alguien más tome decisiones por ellas en ciertas acciones. Un individuo está dispuesto a conformarse porque se siente comprometido con la legitimidad de la fuente del mando y no porque haga una evaluación de la acción o situación implicada. El poder es aceptado porque se considera correcto, justificado o válido en alguna forma y su legitimidad fluye de la internalización de significados culturales (Scott, 2001). Se habla de influencia cuando la persuasión opera a través de símbolos cognitivos, ideas y representaciones que llevan a las personas a definir situaciones en forma específica, es decir, en forma de significación. En este caso, los individuos son atraídos e influenciados por el marco de referencia interpretativo del principal (Scott, 2001). 
Algunos mecanismos de poder son perjudiciales, mientras que otros pueden llegar a ser constructivos. Por ejemplo, la violencia física tiene graves efectos en el bienestar de quien la recibe; sin embargo, la influencia, a través de razonamientos válidos y oportunos, puede ser de provecho para la relación. Por tanto, también se distinguirán entre los mecanismos de poder en las negociaciones relacionadas con la movilidad y trabajo de las mujeres en San Felipe del Progreso.

\section{Metodología}

El trabajo de campo se realizó en dos etapas. En la primera se hicieron entrevistas a profundidad a mujeres de todas las edades y estado civil en dos áreas de San Felipe del Progreso. En este artículo se considera únicamente la información proporcionada por mujeres unidas, casadas $^{2}$ y separadas ${ }^{3}$. Específicamente, las entrevistas se llevaron a cabo en San Lucas Ocotepec, El Carmen Ocotepec, Guadalupe Coté y San Juan Coté. Las primeras dos son localidades que colindan entre sí, al igual que las dos últimas. Las primeras dos comunidades se encuentran cerca y bien conectadas a San Felipe del Progreso y Atlacomulco. Las segundas se encuentran mucho más alejadas de centros urbanos y, por lo tanto, tienen menor acceso a servicios de educación básica superior y superior, a servicios de salud y a empleos fuera de la comunidad. En total se hicieron 18 entrevistas en Guadalupe Coté y San Juan Coté y 22 en San Lucas Ocotepec y El Carmen Ocotepec.

En la segunda etapa,se llevaron a cabo grupos de enfoque en mujeres de toda la zona. Se realizó un grupo de enfoque a mujeres casadas, una a mujeres casadas con migrantes y otra a mujeres separadas. Tanto en las entrevistas como en los grupos de enfoque, se puso énfasis en la dinámica de la relación con sus esposos o exesposos. Se encontró que las mujeres no tenían completa libertad de elegir sobre su movilidad, ya fuera para ir a visitar a sus mamás, para ir al mercado e incluso para trabajar. Esto tenía importantes consecuencias en el bienestar de las mujeres, por lo que se profundizó en la toma de decisiones sobre estos aspectos en el hogar.

\footnotetext{
${ }^{2}$ Para efectos prácticos del presente estudio se considera que las mujeres unidas (que no están casadas por el civil) están casadas, ya que las dinámicas dentro del hogar son las mismas.

${ }^{3} \mathrm{~A}$ las mujeres separadas se les hicieron preguntas sobre la relación con sus esposos cuando estaban unidas.
} 


\section{Características socio-económicas de San Felipe del Progreso}

San Felipe del Progreso es un municipio en el noroeste del Estado de México, que cuenta con 104 localidades. En 2010 tenía una población de 121396 personas. De éstas, 58173 eran hombres y 63223 mujeres. Es considerado como un municipio indígena mazahua, aunque solamente $32 \%$ de la población de 5 años y más hablaba una lengua indígena en el 2010 (INEGI 2010). De acuerdo al Consejo Nacional de Población (CONAPO, 2010), en el 2010 había un índice de marginación alto y de acuerdo a la medición de pobreza del Consejo Nacional de Evaluación (CONEVAL 2015), en el 2010, 81568 personas (80.6 \% del total de la población) se encontraban en pobreza. De ellas, 37611 (37.1\%) presentaban pobreza moderada y $43958(43.4 \%)$ pobreza extrema. Por lo tanto, esta región es pobre y tiene muchas carencias.

Debido a la escasez de oportunidades laborales en el municipio, y a la baja rentabilidad de la agricultura (de subsistencia y autoconsumo), una estrategia económica común en los hogares es la migración de hombres y mujeres solteros a las zonas urbanas. De acuerdo con Larralde (2011), la fuerza laboral agrícola ha emigrado a las zonas urbanas debido a los bajos ingresos en el sector, la disminución de los precios agrícolas, las recurrentes crisis desde 1982 y la restructuración neoliberal. Los estudios llevados a cabo por este autor en Emilio Portes Gil, localidad de San Felipe del Progreso, coinciden con la información obtenida en las entrevistas del presente estudio. Gran parte de la actividad laboral está fuera del espacio local, donde las personas realizan principalmente trabajos por cuenta propia, ya sea en la agricultura, el comercio o en el área de servicios. Aunque gran parte de la población que migra tiene empleo asalariado, no es en ramas altamente productivas o técnicas, por lo que es precario, de baja remuneración y con malas condiciones laborales.

Las mujeres solteras que migran se dirigen principalmente a la Ciudad de México a trabajar como empleadas domésticas, aunque también se encontraron mujeres que migraban a Hermosillo e incluso a Estados Unidos. Una vez casadas, las mujeres regresaban a los pueblos y vivían con sus suegros. Este también era una estrategia económica, ya que una vez formada una familia era inasequible mantener el hogar en la ciudad. Una vez que los esposos ahorraban (que no siempre ocurría) podían adquirir un inmueble e independizarse de la familia política. 
Las parejas se distribuían las labores de acuerdo a las normas sociales prevalecientes, es decir, las mujeres realizaban las labores domésticas y los esposos proveían económicamente. Las labores domésticas incluían el limpiar la vivienda, hacer la comida, servirla a los miembros del hogar, cuidar a los niños, ancianos y enfermos, cuidar a los animales y trabajar la tierra. Por otra parte, no había muchas oportunidades de trabajo extradoméstico en la zona para las mujeres, pero se encontraron otras, como lavar ajeno, trabajar la tierra de otros, en una estética, atendiendo tiendas y en empleos informales, como la venta y preparación de comida y la venta de ropa. Las mujeres con mayor nivel educativo eran enfermeras o maestras.

Los hombres, solteros o casados, migraban a la Ciudad de México (en cuyo caso regresaban a sus pueblos cada fin de semana) o a Estados Unidos. En estos lugares era común que trabajaran como obreros en la industria de la construcción. Aquellos que migraban a Estados Unidos tenían un mayor estatus, ya que podían enviar más dinero a sus familias. Otros oficios de los hombres eran chofer de taxi, agricultor y microempresario informal, por ejemplo, en venta de pan.

\section{Dinámicas de poder en el hogar relacionadas con la movilidad de las esposas}

En San Felipe del Progreso muchas mujeres no tienen libertad de salir de sus casas para ir a donde ellas elijan. Una norma social imperante en el municipio indica que las mujeres que viven en pareja tienen que pedir permiso a sus esposos y suegros para ir a lugares alejados, tales como el mercado, visitar a su familia o ir a trabajar. Al tener que pedir "permiso" y estar sujetas a éste, las mujeres viven bajo la autoridad de la familia política, que tiene el poder de decisión sobre las vidas de las esposas.

Cuando las esposas querían salir de sus casas y sus esposos rechazaban que lo hicieran, se debía principalmente a dos motivos, ambos relacionados con las normas sociales. El primero está vinculado con la preocupación de los esposos de que sus esposas les pudieran ser infieles. Por ejemplo, Paola indica que a su esposo: "No le gusta que salga, porque cree que va a haber hombres. Cree que hay otras personas que pueden llamar mi atención. Ya sabe que van puras mujeres pero, cuando hay hombres sí se pone celoso". Entonces se ejercía control en la sexualidad de las mujeres a través de la restricción de sus movimientos. Los esposos tampoco querían que sus esposas salieran porque si lo hacían no cumplirían 
cabalmente con sus tareas de amas de casa, es decir, no tendrían lista la comida a tiempo o no los atenderían a ellos como creían que era debido. Por ejemplo, Carmen indica que tiene conflictos con su esposo: "Luego me iba a casa de mi mamá todo el día y cuando llegaba él me decía 'y ahora tú, ¿dónde te metes? ¿Por qué no me has preparado de comer?” Ambos motivos están directamente relacionados con las normas sociales.

Cuando los esposos migraban se encontraron casos en los que seguían controlando los movimientos de sus esposas por teléfono. En otros casos sólo controlaban su movilidad cuando ellos estaban presentes. No obstante, cuando las esposas viven con su familia política no sólo tienen que pedirle permiso a sus esposos, sino también a sus suegros. Por lo tanto, la migración de los esposos no significa completa libertad de movimiento para ellas; sin embargo, sí significa que dichas esposas, después de tener hijos y de que éstos se casaran, podían tener poder sobre la decisión de movilidad de otras mujeres: sus nueras.

Aunque la esposa no esté viviendo con la familia política, ésta puede controlar y vigilar sus movimientos por medio de chismes y críticas, los cuales están relacionados directamente con las dos normas mencionadas, es decir, con el cumplimiento de las esposas de su rol de ama de casa y también con el control de su sexualidad.

Un ejemplo del primer caso es el de Celia. Su esposo es un obrero que trabaja entre semana en la Ciudad de México. A él no le importa que ella salga; sin embargo, el hermano de él insiste en que Celia debe permanecer en su casa:

Haga de cuenta que no le gustaba que yo saliera, que no llegara nadie a la casa, quería que todo el tiempo una estuviera en la casa, en la casa, y pues yo cuando recién me fui para allá venía seguido con mi mamá, diario, diario, y eso era lo que no le gustaba a ese señor. Me decía que si su hermano me vino a traer era para que me quedara en la casa y no para que anduviera de aquí para allá y que esa casa la tenía que cuidar.

Ejemplo del segundo caso es el de Rocío, a quien su esposo cela. Él también trabaja como obrero en la Ciudad de México y su mamá le siembra celos. Rocío dijo: “Su mamá (de su esposo) le da ideas, le dice que yo salgo, que todo el tiempo estoy fuera, y entonces se pone celoso. Como él esta fuera, está trabajando fuera”. 
Cuando los esposos no les daban permiso a sus esposas de salir, a veces ellas buscaban negociar abiertamente con ellos para tratar de convencerlos, pero esto podía ocasionar que reforzaran su autoridad con violencia, ya fuera verbal o físicamente.

Celia, también manifestó:

Hay veces que no me da permiso. "No quiero que vayas y punto. Si no quieres tener más problemas, no vayas; tú decides". A veces sí le hago caso y no voy, pero a veces le digo que no soy propiedad de él. Hay días que sí se pone muy agresivo y como a veces toma, es cuando saca toda su furia. Ya no me golpea, pero se desquita con las cosas, avienta los trastes y nos insulta muy feo (a ella y sus hijos).

Este es un caso de poder visible, donde la esposa trata de resistir la autoridad de su esposo de forma explícita y abierta, al decirle que ella no es de su propiedad. El esposo respondía intentando imponer su autoridad con amenazas y violencia.

Otro mecanismo de oposición de las esposas es la resistencia oculta, con la que ellas deciden a dónde ir, a pesar de no contar con el permiso de la familia política. Consiste en encubrir acciones reales para poder hacer lo que ellas quieren. Lucía, por ejemplo, de 52 años, y que vive en Guadalupe Coté, indicó que su esposo no le da permiso de ver a su mamá. Al preguntarle qué hace en esos casos, contestó:

Pues le decía que iba a la tienda o algo así y me iba rápido con mi mamá o, por ejemplo, los días domingo yo le decía: "Mira, voy a ir a Santa Ana" (pueblo donde está el mercado) y él me decía: "Está bien". Y como mi suegra vive cerca, mi mamá vive más arriba y mi suegra más abajo, ahí era donde yo aprovechaba, o cuando iba a la escuela con los niños que había reunión de ahí ya me pasaba.

Guadalupe aprovechaba las salidas a otros lugares para ir a ver a su mamá, sin que su esposo se diera cuenta. Este mecanismo, además de ocultar las acciones reales de las mujeres, implica que tenían que esperar el momento adecuado. No podían hacerlo en el momento en que ellas quisieran, así que aunque había un mecanismo de poder oculto, distaba de ser una libertad completa de decisión.

Es interesante notar que Lucía, quien ahora vive con su hijo y su nuera, se queja de que ella dice que va a otro lugar cuando en realidad va a ver a su mamá. 
Ella que se va con sus papás y luego me dice mi esposo que por qué la dejo, pero yo le digo que quién soy yo para prohibirle y de hecho ella me dijo que ella se casó con mi hijo, no conmigo y se desquita conmigo mi esposo. En la mañana me dice "Suegra, ya me voy", luego me mandó un mensaje: "Mi cuñada está muy enferma". Y ya resulta que llegó mi esposo y me pregunta y ya le digo que dice que se puso enferma su cuñada, y dice: "Pues está mal, ya se la agarró que cada ocho días a su casa". Yo voy a preguntarle a su papa qué pasa y dice que la única que salió fue su mamá, y la cuñada que según estaba enferma andaba por el cerro cuidando.

La nuera de Lucía resistía abiertamente el poder que su suegra tenía sobre su movimiento, pero aun así tenía que recurrir a encubrir su verdadera intención para poder ir a ver a su familia, así que en realidad no tenía completa autonomía para ir a donde ella quisiera.

A partir de los ejemplos mostrados hasta ahora, se hace evidente, como lo había expuesto Gaventa (2011), que las formas y mecanismos de poder relacionados con una misma decisión están interrelacionados y varían en el tiempo. La nuera de Lucía, por ejemplo, resiste abiertamente en ocasiones la autoridad de su suegra, diciéndole que se casó con su hijo, no con ella, y también oculta sus verdaderos movimientos. Los esposos además de la autoridad que ejercen, en ocasiones utilizan la violencia para reforzar su autoridad.

Por otra parte, se encontraron también varias mujeres que indicaron que cuando pedían permiso para salir y su esposo no se los daba, acataban su decisión sin negociar para que cambiaran de opinión. Es decir, cedían todo el poder a su esposo de elegir sobre su movilidad. Internalizaban así la norma que indica que los esposos tienen autoridad sobre las esposas.

Había mujeres que incluso habían internalizado la noción de que las mujeres debían quedarse en su casa. Por ejemplo, Josefa señaló: "Él (su esposo) trabaja en México, yo no salgo de mi casa, de misa me voy a comer. Si llego a salir, le aviso por teléfono”. Cuando ya no se cuestionan estas normas sociales y comienzan a percibirse como una conducta natural a seguir, se habla de un poder invisible.

Por último, sobre todo entre las nuevas generaciones, los esposos invitan a sus esposas a que no pidan permiso, es decir, ellos otorgan a sus esposas el poder de decidir sobre su movilidad. Fabiola de 32 años, por ejemplo, dijo: "Yo no le pido permiso a mi esposo, él 
me dice: 'a mí solamente avísame, yo no necesito que me pidas permiso, sólo avísame'. Sólo es avisarle a donde voy".

\section{Dinámicas de poder en el hogar relacionadas con el trabajo extra-doméstico de las esposas}

Se ha reiterado a lo largo del artículo que las normas sociales en la región indican que las mujeres casadas son amas de casa, es decir, son las responsables de la limpieza del hogar; de atender a sus miembros, incluyendo cocinar y servir la comida; de cuidar a los niños, viejos y enfermos; y de ocuparse de los animales de la casa. Al casarse, muchas mujeres viven con sus suegros, por lo que realizan dichas tareas bajo la autoridad de sus suegras. Los hombres, por otro lado, son los proveedores del hogar. Las mujeres del grupo de mujeres separadas afirman que: "El señor tiene que salir a trabajar y la señora tiene que lavarle". Por lo tanto, las normas sociales establecen las tareas que las mujeres deben realizar.

En ausencia de normas sociales, los miembros del hogar negociarían por una división de tareas de acuerdo a sus preferencias. Sin embargo, debido a estas normas cada miembro de la familia se dedica a tareas dentro y fuera del hogar de acuerdo a sus roles.

Muchas mujeres de San Felipe del Progreso desean trabajar fuera del hogar para tener los medios que les permita adquirir bienes y tener una independencia económica, sobre todo si habían migrado y trabajado cuando eran solteras. Al casarse, las mujeres regresaban a su pueblo y asumían el rol de ama de casa. Varias entrevistadas que habían migrado indicaron que extrañaban tener la autonomía de decidir sobre sus propios ingresos.

Me acostumbré a tener mis cosas; si quería algo me lo compraba. Ahora se me hace muy difícil, porque si quiero comprar cosas para mi hija o para mí misma y mi esposo no me da, me quedo con las ganas de comprar las cosas. Por eso me gustaría trabajar.

Por su parte, Adriana también señala que extraña trabajar, ya que "me hacía sentir independiente y ahorita pues ya dependo de alguien, no sólo de mí’. Aunque las mujeres no 
hubieran trabajado de solteras, de todas formas trabajar es la forma en la que pueden adquirir bienes para ellas y ahorrar dinero.

En la negociación de si las esposas trabajan o no, las normas sociales también favorecen que los esposos tengan autoridad sobre ello. Cuando las esposas negocian con sus esposos poder salir a trabajar (en la movilidad, los hombres se niegan por celos y porque ellas "descuidan sus obligaciones de amas de casa") se pone énfasis en el cuidado de los hijos,

Este era el caso de Fabiola, de 20 años, quien platicó que había tratado de convencer a su esposo de que le diera permiso de trabajar: "Pues a veces cuando yo tenía nada más dos niños quería irme a trabajar, pero pues él no quiso y pues ya nunca lo convencí y ahorita con cinco, pues menos". Al preguntarle porqué su marido no había querido que ella trabajara, contestó "Pues lo que pasa es que los niños ya iban a la escuela y luego no había quién los cuidara para que se fueran a la escuela. Por eso".

Incluso aquellas mujeres que tenían dónde dejar a sus hijos indicaron que sus esposos no querían que trabajaran porque descuidaban a sus hijos. Gabriela trabajó un tiempo en Toluca y mientras lo hacía vivió con su hermana, quien cuidó a su única hija.

Hace poquito me fui a trabajar a Toluca. Le dije: "Me voy a desaburrir", pero ya no me dejó por mi niña. Yo estaba en donde venden jugos, licuados, tortas y todo eso. Es que había dos turnos: entraba de las seis de la mañana a las dos y media de la tarde, o luego entraba de las ocho de la mañana a las seis y media de la noche. Entonces llegaba yo y mi hija ya estaba durmiendo, y ya por eso no me dejó.

Lo esposos argumentan que no querían que sus esposas trabajaran porque era su obligación cuidar a los hijos. Mientras que éste podía ser un motivo auténtico por el cual los esposos no querían que sus esposas trabajaran, también y debido al peso que tiene para las esposas y la sociedad entera el ser buena madre, podían haberlo utilizado para persuadirlas de no trabajar. 
Por ejemplo, Martha tiene una niña de año y medio. Ella dijo que su esposo no accedía a que ella trabajara.

He platicado con él y pone de pretexto a la niña. Para él sí es pretexto. ¿Qué va a decir la gente si la esposa de tal persona está trabajando si él acaba de llegar de Estados Unidos? ¿Qué va a decir la gente? Le importa lo que dice la gente.

Martha piensa que su esposo no quiere que ella trabaje porque le interesa su imagen de proveedor económico, en especial porque acaba de regresar de Estados Unidos, de donde se supone debió haber ganado mucho dinero, y no tanto el cuidado de su hija. Esto asimismo pone en evidencia, la influencia de los chismes y críticas (que siempre surgen cuando una esposa trabaja) en las motivaciones y preferencias de las personas.

Por ejemplo, Lorena dijo que tenía roces con su esposo y que también recibía críticas de su suegra y familia política porque trabajaba.

Entre la familia, el que te ausentes todos los días, de lunes a viernes, de tales horarios a tales a horarios, no es bien visto. Me decían que no iba a trabajar... que yo era mala madre, que cómo podía dejar a mis hijos, me decían groserías, pero no tomaba en cuenta los comentarios que ellas hacían.

Por lo tanto, estos chismes y críticas se basaban tanto en la idea de que las mujeres que trabajan descuidan a sus hijos, y a la de que había la posibilidad de que fueran infieles a sus esposos si se ausentaban de la casa.

También está la creencia de que un hombre se casa para que la esposa le limpie, le cocine, le cuide a sus hijos, etcétera. Los suegros de Martha, por ejemplo, le decían a su esposo “Entonces para qué te casaste, entonces para qué quieres a tu mujer si ya se deslindó de las obligaciones que tiene, de hacerte de comer, te lavarte o atenderte?"

Si las mujeres se resistían abiertamente a la autoridad de sus esposos, podía ocasionar la disolución del matrimonio. Este fue el caso de Claudia. Con el apoyo económico de sus 
papás ella estudió enfermería y trabajaba en un centro de salud. Mientras trabajaba, su mamá le cuidaba a sus tres hijos, uno de trece y dos gemelos de ocho años de edad. Cuando todavía estaban casados, su exesposo, quien había migrado a Estados Unidos, no quería que ella trabajase. Aunque no vivía en San Felipe, él se ponía celoso por las horas en las que ella llegaba a su casa.

Tenía dificultades porque "no has llegado, es que llamé, marqué a la casa y nos has llegado." Igual incomoda y con el tiempo te va afectando. Y yo digo nueve años estuvieron bien. Yo digo no importa, no importa, bueno sí importa porque no trabajas a gusto, no vives a gusto. La verdad, sí importa.

Igual que con el caso de la movilidad, aunque los esposos hubieran migrado las mujeres tenían que rendirles cuentas por teléfono. En este caso, eventualmente su esposo la había dejado y había encontrado otra pareja en Estados Unidos. Claudia se sentía culpable de haber trabajado, pensaba: "De repente si no te hubieras ido a trabajar no estarías sola, con estos tres hijos". Por lo tanto, ella relacionaba el abandono de su esposo con que ella no hubiera respetado su autoridad, ignorado la desaprobación de su familia política y tomado la decisión de trabajar.

Aquí también estaba presente un poder invisible, pues debido a que las mujeres habían internalizado las normas sociales y creído que su obligación era ser amas de casa y no trabajar, renunciaban a la negociación con sus esposos.

Está claro que un trabajo requiere ausentarse del hogar en un horario durante varios días a la semana. Esto hizo que el tema de la movilidad fuera diferente del laboral en dos aspectos. El cuidado de los hijos era más relevante que las labores domésticas. Sin embargo, aunque las mujeres tuvieran quién las ayudara a cuidar a sus hijos (casi siempre un familiar cercano), se tenía la percepción de que los descuidaban si trabajaban. Además, al contrario de la movilidad, no se encontró una forma de poder oculta ya que resulta mucho más difícil ocultar el trabajo que unas visitas fuera del hogar. 


\section{Discusión}

Como se ha corroborado hasta ahora, son varios los canales por los cuales las normas sociales influyen en el poder de las mujeres. En primer lugar, las normas sociales establecen cuáles son las actividades y comportamiento adecuados para hombres y para mujeres. Las mujeres deben quedarse en casa, ser fieles, dedicarse a las labores domésticas y al cuidado de los miembros de la familia. Por otro lado, los hombres deben ser los proveedores. Hay parejas que internalizan estas normas sociales al grado de que no las cuestionan. En este caso, está presente un poder invisible que limita a las mujeres en su libertad de movimiento y de elección de trabajar y, por lo tanto, de tener bienestar. Algunas mujeres internalizaban estas normas a tal grado que incluso mencionaban que no salían de sus casas, es decir, ni siquiera se atrevían a pedir permiso a sus esposos para salir.

Las normas sociales también dan autoridad a los esposos y las familias políticas con respecto a su incumplimiento en la movilidad y trabajo extra-doméstico de las mujeres. En ese sentido, las mujeres no son consideradas como personas adultas y críticas, con derecho a decidir sobre su propia movilidad.

Cuando las esposas negocian visiblemente con sus esposos que las dejen salir de sus casas o ir a trabajar, y no acceden, se debe principalmente a dos motivos, ambos relacionados con las normas sociales. En primer lugar, en el municipio hay un fuerte control de la sexualidad de las mujeres, una gran sospecha y desconfianza relacionada con la fidelidad a sus esposos. Si las esposas salen o trabajan levanta sospechas de que puedan conocer a hombres con los que serán infieles.

En segundo lugar, las esposas al ser amas de casa tienen que atender a los miembros de la familia y realizar las labores domésticas, como cocinar y servir la comida. Incluso se considera que estas tareas son el propósito mismo de las mujeres en el matrimonio. Por lo tanto, si las mujeres salen lejos o trabajan no pueden cumplir cabalmente con dichas obligaciones. Asimismo, las mujeres que trabajan tienen que ausentarse más tiempo, por lo que se piensa que descuidan el cuidado de los hijos.

Además, las normas sociales influyen en las motivaciones y preferencias, tanto de los esposos como de las esposas, a través de los chismes y las críticas de la familia política y la 
sociedad en general. De esa manera limitan la libertad de movimiento de las mujeres y su trabajo fuera de casa.

En el proceso de negociación, el cuidado de los hijos también se utiliza para impedir que las esposas trabajen, aunque no sea este el verdadero motivo. Así que las normas sociales también son utilizadas como argumentos en el proceso de negociación.

Las normas sociales influyen en los argumentos utilizados. Se recomienda hacer campañas de concientización para contrarrestarlas.

Los esposos de aquellas mujeres que transgredían visiblemente su autoridad recurrían a la violencia, ya sea verbal o física, para amedrentar. Esto evidencia la teoría de la inconsistencia de estatus, que indica que los esposos son más proclives a emplear la violencia si se sienten amenazada su autoridad o no pueden cumplir con su papel de proveedores (Casique 2008). Al elaborar programas y políticas para empoderar a las mujeres, deben de considerarse los efectos perniciosos que se pueden generar, tal como una mayor violencia por parte de los esposos. Es fundamental considerar programas que atiendan a los hombres sobre los efectos de su pérdida de identidad en relación con su autoridad y jerarquía en el hogar.

Por otra parte, las mujeres pueden utilizar un mecanismo de resistencia o poder oculto, con el que logren ir a donde ellas quieran, pero encubriendo sus acciones. Si dicen que van a otros lugares o esconden el verdadero motivo de sus salidas de casa, logran el poder para ir a donde ellas quieran. No obstante, este mecanismo de resistencia por ser oculto dista de ser una verdadera libertad. Así, es evidente la importancia de mejorar la capacidad que las mujeres tienen de expresarse y manifestar sus necesidades asertivamente.

A pesar de que las normas sociales en San Felipe otorgan autoridad a los esposos de tomar decisiones relacionadas con la movilidad y trabajo de sus esposas, existen algunos que las invitan a que decidan ellas mismas sobre el asunto. Esto sucede sobre todo en las nuevas generaciones. Se recomienda identificar claramente cuáles son los factores, tales como educación, participación de las mujeres en trabajos asalariados, etcétera, que influyen en la internalización de las normas sociales entre hombres y mujeres, para alcanzar relaciones de poder más equitativas. 
Por otro lado, aunque los esposos den esa libertad a sus esposas, la familia política puede limitarla a través de chismes y críticas, por lo que se deben crear programas para erosionar las normas sociales en toda la comunidad y no sólo tratar de influir aisladamente en un puñado de mujeres.

Aunque en el presente artículo se estudió la influencia de las normas sociales en el poder de las mujeres en las relaciones de pareja, sería interesante hacerlo con la influencia de las normas sociales en el poder de las mujeres a nivel comunitario y en sus interacciones con las instituciones. Vale la pena repetir el estudio en otras regiones para identificar las similitudes y diferencias entre los mecanismos y visibilidad del poder de las mujeres a nivel relacional. Incluso podría plantearse un estudio cuantitativo para conocer el alcance de las normas sociales y sus formas de poder en las relaciones.

\section{Conclusión}

Del estudio aquí presentado se hacen evidentes dos cuestiones: la importancia de ahondar en las dinámicas de poder en el hogar, y la necesidad de examinar a fondo los canales a través de los cuales las mujeres se empoderan. Sólo de esta manera se pueden esgrimir programas y políticas encaminados a incrementar el bienestar de las mujeres.

Diferenciar los mecanismos de la visibilidad en la negociación en el hogar es esencial. Por ejemplo, los esposos buscan imponer su autoridad con violencia. Esto conlleva que para poder empoderar a las mujeres es necesario encontrar formas de mejorar su agencia y recursos, pero también de educar a los hombres para que sean conscientes de la libre determinación de sus esposas.

Asimismo se debe indagar sobre las normas que limitan el poder de las mujeres en el hogar. La autoridad de los esposos sobre sus esposas, el control de la sexualidad de las mujeres, y los roles de ama de casa y de proveedor económico, son normas sociales que impiden la libertad de las esposas en su movimiento y trabajo extra-doméstico. Por lo tanto, dichas normas sociales deben combatirse con programas de concientización, talleres, etcétera.

Finalmente, las normas sociales a través de la internalización y de los chismes y críticas. La mujer que desafía las normas que limitan su libertad, encontrará obstáculos y presiones por parte de su esposo, su familia política y las personas de su localidad. Así, las normas sociales deben ser erradicadas de las localidades. 


\section{Bibliografía}

Boserup, E. (1970). Women in economic development. London: Earthscan.

Casique, I. (2007). El complejo vínculo entre empoderamiento de la mujer y violencia de género. En: Roberto Castro e Irene Casique (coords.) Estudios sobre cultura, género y violencia contra las mujeres, vol. 1. México: UNAM, 231-260.

CONAPO (2010). Índice de marginación por entidad y municipio. Consejo Nacional de Población: México. Disponible en:

http://www.conapo.gob.mx/es/CONAPO/Indices_de_Marginacion_2010_por_entidad_fede rativa_y_municipio

CONEVAL (2015). Pobreza a Nivel Municipio 2010. México: Consejo Nacional para la Evaluación de la Política de Desarrollo Social. Disponible en: http://www.coneval.org.mx/Medicion/MP/Paginas/Medicion-de-la-pobrezamunicipal-2010.aspx

Covarrubias, A. (2016). La sombre voluntaria. Normas sociales y participación laboral de las mujeres en la maquila. Estado de México: El Colegio Mexiquense, A.C.

García, B. y Oliveira, O. (1994). Trabajo femenino y vida familiar en México. Ciudad de México: El Colegio de México.

Gates, L. (2002). The Strategic Uses of Gender in Household Negotiations: Women Workers on Mexico's Northern Border. Bulletin of Latin American Research (21)4: $507-526$

Gaventa, J. (2011). Power Pack, Understanding Power for Social Change. Disponible en:http://www.powercube.net/wp-content/uploads/2011/04/powerpack-webversion-2011.pdf

INEGI (2010). Censo de Población y Vivienda. Instituto Nacional de Estadística y Geografía: México.

Kabeer, N. (1999). Resources, Agency, Achievements: Reflections on the Measurement of Women's Empowerment. Development and Change (30)3: 435-464.

Kabeer, N. (2000). The Power to Choose; Bangladeshi Women and Labour Market Decisions in London and Dhaka. London: VERSO. 
Larralde, A. (2008). Mercados de trabajo en localidades rurales del centro de México: algunas características sociales y espaciales. En Kirsten Appendini \& Gabriela Torres (coords.) ¿Ruralidad sin agricultura?, El Colegio de México: México: 79102.

Lukes, S. (2005). Power: a Radical View, vol. 2. Basingstoke: Palgrave Macmillan in association with the British Sociological Association.

Malhotra, A., Schuler, S. y Boender, C. (2005). Measuring Women's Empowerment as a Variable in International Development. Background Paper. Washington: World Bank.

Nussbaum, M. (2000). Women and Human Development: the Capabilities Approach. Cambridge: Cambridge University Press.

Scott, J. (2001). Power (Key Concepts). Cambridge UK: Polity Press.

Rutherford, M. (1996). Institutions in Economics: The Old and the New Institutionalism. Cambridge: Cambridge University Press.

Sen, A. (1987). Gender and Cooperative Conflicts. WIDER Working Papers WP 18.World Institute for Development Economics Research. United Nations University.

\section{Agradecimientos}

Agradezco al Programa para el Desarrollo Docente (PRODEP) de la Secretaría de Educación Pública por financiar el proyecto de investigación, así como a las integrantes de la Casa de la Mujer Indígena ZANA JÑATJO, Luna Mazahua en San Felipe del Progreso, por su apoyo logístico y apertura para entrar a sus comunidades. Asimismo agradezco el apoyo de la Dra. Luz María Salazar y sus sugerencias para la elaboración de este trabajo. 